\title{
Multivariate Chemometric Analysis of a Polluted River of a Megalopolis
}

\author{
Alejandro Gabriel García-Reiriz ${ }^{1 *}$, Jorge Federico Magallanes ${ }^{2}$, Marjan Vracko ${ }^{3}$, Jure Zupan ${ }^{3}$, \\ Silvia Reich ${ }^{4}$, Daniel Salvador Cicerone ${ }^{2,5}$ \\ ${ }^{1}$ Department of Analytical Chemistry, Faculty of Biochemical and Pharmaceutical Sciences, National University of Rosario, Rosario \\ Institute of Chemistry (IQUIR-CONICET), Rosario, Argentina; ${ }^{2}$ Gerencia Química, Comisión Nacional de Energía Atómica (CNEA), \\ Buenos Aires, Argentina; ${ }^{3}$ National Institute of Chemistry, Ljubljana, Slovenia; ${ }^{4}$ Universidad Nacional de General San Martín. San \\ Martín, Argentina; ${ }^{5}$ Instituto de Investigación en Ingeniería Ambiental - 3iA, Universidad Nacional de General San Martín,. San \\ Martín, Argentin. \\ Email: garciareiriz@iquir-conicet.gov.ar
}

Received April 28 ${ }^{\text {th }}$, 2011; revised June 27 ${ }^{\text {th }}, 2011$; accepted August $8^{\text {th }}, 2011$.

\begin{abstract}
A chemometrical study regarding a 10-years water quality monitoring plan at 15 sampling points along a section of the Reconquista River and its stream channels, which embraces 21 campaigns, is presented. The original data were pre-treated in order to eliminate missing data and outliers, obtaining a final data matrix of 270 samples containing 26 physical-chemistry variables each. Multivariate statistical methods like multi curve resolution, canonical correlation analysis and factor analysis methods, as well as current univariate statistics were applied. The interpretation was simplified when variables were separated in groups containing environmentally and chemically related variables instead of analyzing them all together. These methods have shown that the presence of metals likely come from at least 3 different type of sources. Although the stream channels arriving to the main river course are highly polluted, their flow rates are so low that do not significantly decrease its water quality. They mainly contribute to the high levels of biochemical-oxygen demand and chemical-oxygen demand as well as nitrogen-content species. Furthermore, regarding metals, the pollutants coming from the upstream of the river is higher than those introduced by all channels.
\end{abstract}

Keywords: Surface Water, Water Pollution, Chemometric, Multivariate Statistic

\section{Introduction}

It is clear today that fresh-water flows are an essential human resource for the mankind. About $20 \%$ of normal flow of world's rivers is used by humankind's necessities like agriculture, hydropower and domestic use. As a consequence, several activities water-dependent resources, like agricultural and industrial as well as heavily dense populated cities with inadequate sanitary infrastructure, have seriously compromised the quality of surface waters because agricultural runoff, the introduction of heavy metals by industrial untreated waste, organic persistent compounds and pathogens. Furthermore, the shanty towns waste the dirty water by channelling it into the sewer to the surface water flows. The discharge of untreated wastewater is a growing environmental concern, with many rivers being turned into open sewers. Only about 10 percent of wastewater in developing countries is collected and only about 10 percent of existing wastewater treatment plants operate reliably and efficiently [1]. As a consequence, many downstream populations receive water of low quality, unsuitable for domestic use and protection of aquatic life.

When river water approaches to the lowlands their transported contaminants impact the low basin area, particularly in the coastal zones, where more than half of the world's population lives. As a matter of fact, 12 out of 17 world's mega cities, whose populations are grater than 10 millions are located at coastal zones, confirmed Environment Matters (2003).

In Argentina, Buenos Aires City and its suburbs is one of the coastal megalopolis having more than 11 millions of inhabitants. The Matanza-Riachuelo and Reconquista rivers are both the two most polluted rivers of the district. Both of them flow into Rio de la Plata Estuary. A local 
study [2] reported that this estuary is $30.212 \mathrm{~km}^{2}$; with a river flow rate of $18.000 \mathrm{~m}^{3} / \mathrm{s}$; being the source of drinkable water for Buenos Aires's inhabitants.

The middle basin of the Reconquista River is being studied by interest of the San Martín Municipality (see Figures 1-3). Three affluent channels are located in this sector, which collect non treated effluents and solid waste coming from industries and populated irregular settlements. These are low flow channels in comparison with the river, but they are highly polluted.

The Arroyo Moron stream comes from highly industrialized areas; it is larger than the channels and tributes to the Reconquista River next to the initial part of the sector under study. Another remarkable fact is the presence of two landfills on the shore of this sector, one of them is presently being filled and the other was closed in January

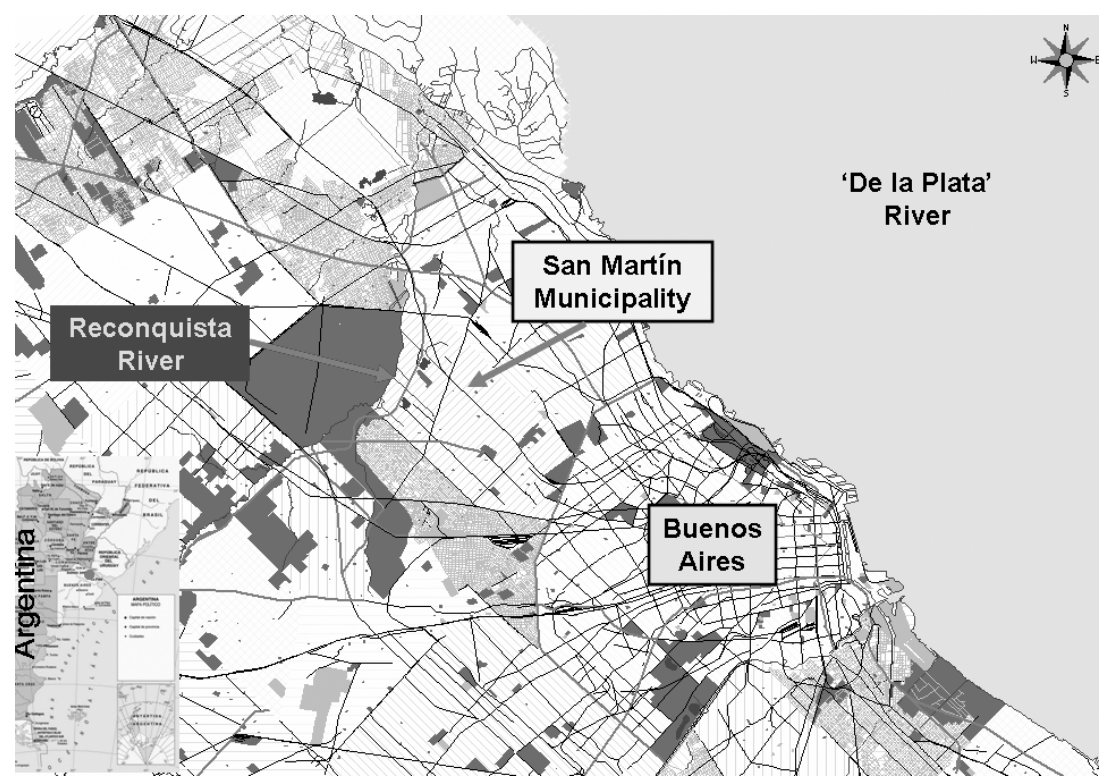

Figure 1. Location of Reconquista River in Buenos Aires Province. It flows to Río de la Plata River.

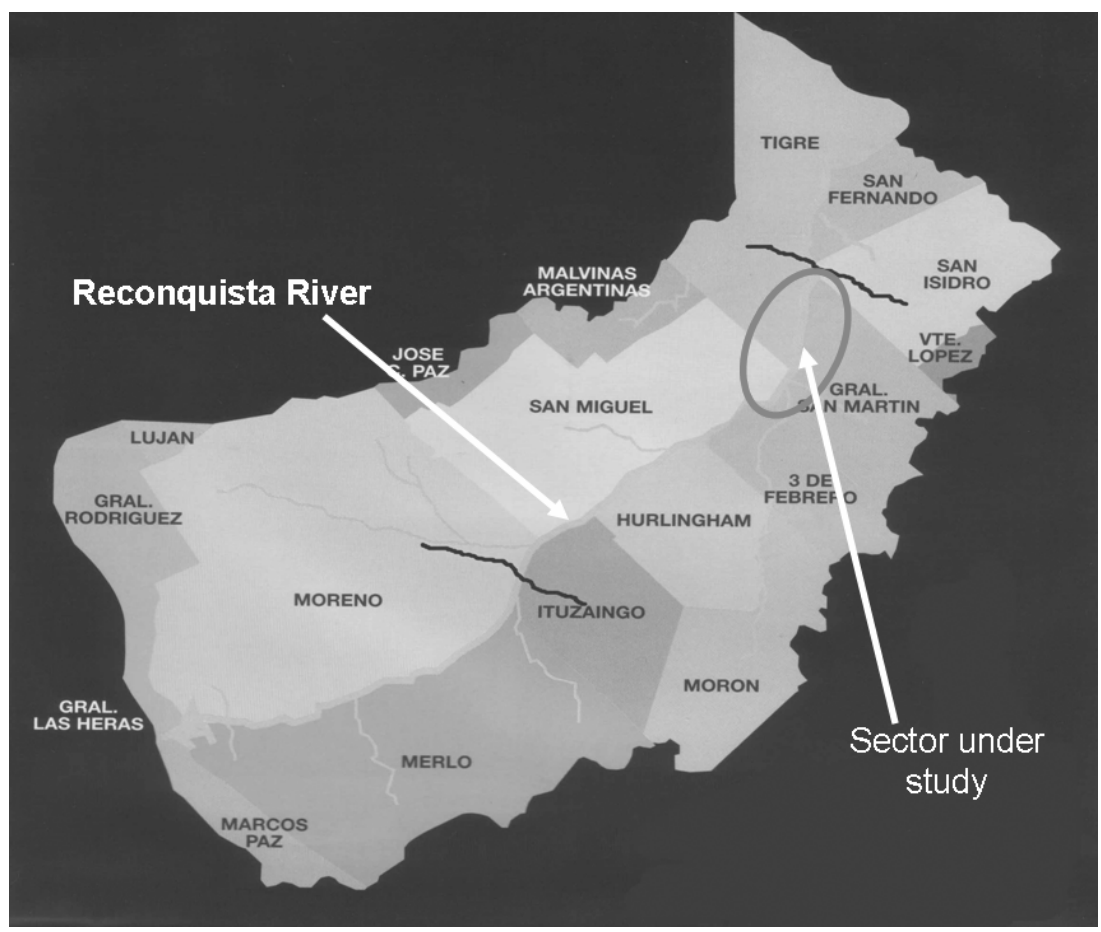

Figure 2. Close sight of the sector under study in the Reconquista River. 


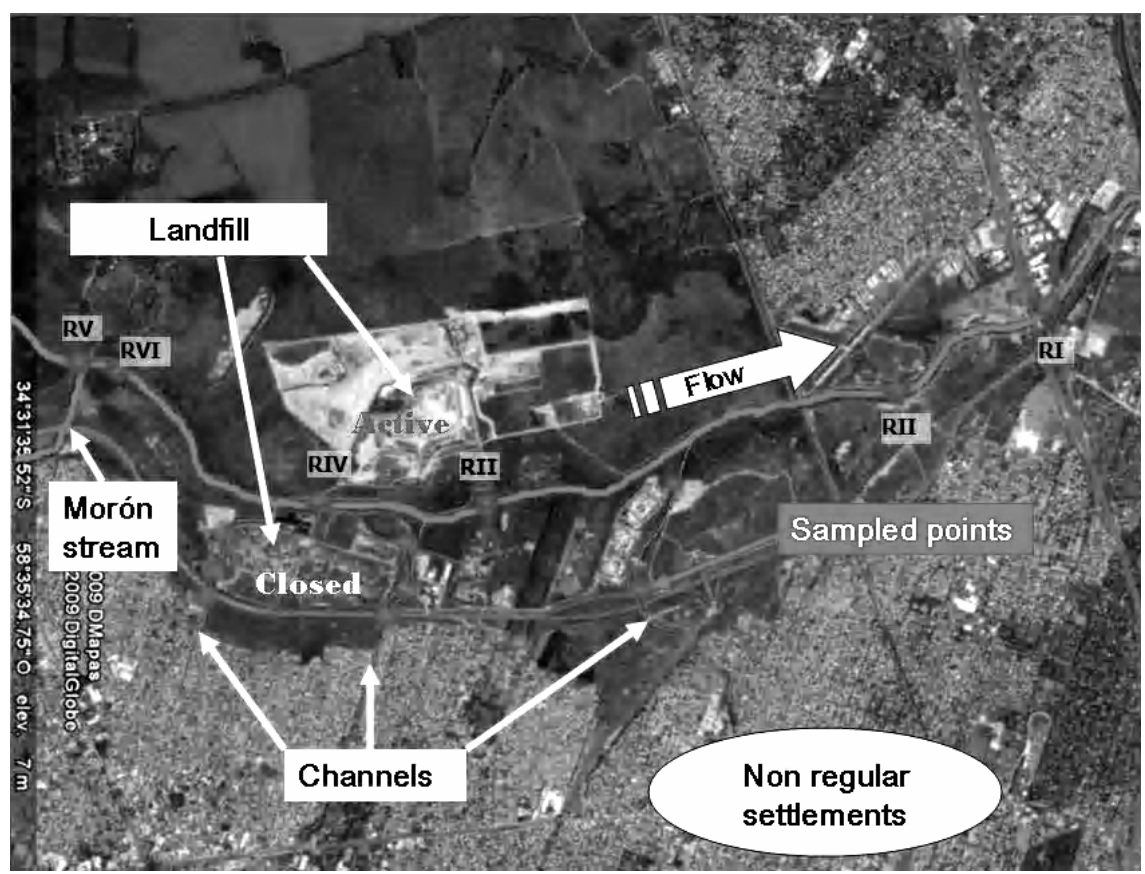

Figure 3. Detailed sight of the sector under study showing sample points and main geographical features.

31, 2004, but it is still biologically and chemically active.

Environmental systems are rather complex to interpret because the amount of different variables required to be taken into account and the complicate relationships among them. These characteristics determine that the data have to be processed by chemometrical techniques and particularly by multivariate statistical methods. The description and interpretation of environmental systems requires the development of mathematical models of two different kinds. One of them is the mechanistic model [3], which try to describe the system applying a combination of known basic scientific laws, like mass transport, chemical equilibrium, thermal and mechanical convection, etc. The other one, which is of our specific interest here, applies statistical and computational methods based on different strategies, but with the same objective. This methodology of analysis includes several multivariate statistical techniques like clusters, principal components and factor analysis, partial least squares, artificial neural networks, etc. All these methods are widely described, for instance, in the following References: [4-7].

This work presents a first water-pollution analysis of the Reconquista River and its present state. The concept of studying a partial section of the river instead of the complete basin meets the requirement of intensive sampling with a low budget.

\section{Sampling and Data Base}

Samples were collected during a period of 10 years, 1995-2005. Sample points are shown in Figure 3. Two or three sampling campaigns were carried out every year. Samples were taken at all sites during the same day.

After elimination of variables with few measurements or occasional sample points with lack of information, we obtained a complete data base matrix $\mathrm{M}_{270 \times 26}$ of 270 samples with 26 measured variables each, which are shown in Table 1.

Analytical chemistry methods were carried out under appropriate normalized procedures for every variable.

Most variables have a lognormal distribution and a few of them are normally distributed. Those variables values recorded as zero were changed to the average between the detection's limit of the method and zero. When comparisons among them altogether were necessary, they were scaled to 0 - 1 range using a minimax algorithm:

$$
x_{s}=\frac{x-x_{\min }}{x_{\max }-x_{\min }}
$$

where $x_{\mathrm{s}}$ is the scaled value, $x$ is the original value, and $x_{\min }$ and $x_{\max }$ are the extremes of its range. For instance, Figure 4 shows spreads of all 26 variables. It would have been impossible to show them altogether with their original units because of their different scales. This figure also shows the extreme values of many variables, which strongly affect the results of calculus, thus needing them to be analyzed as outliers or not. Different criteria have been used to remove (or not) extreme values shown in Figure 4: robust Mahalanobis detection [8] and professional judgmental. Further analyses have been made on this data base, either scaled or with its original unities. 
Table 1. Physical and chemical measured variables and used acronyms.

\begin{tabular}{|c|c|}
\hline Variable & Acronym \\
\hline Alcalinity & $\mathrm{Al}$ \\
\hline Arsenic & As \\
\hline Cloride & $\mathrm{Cl}$ \\
\hline Conductivity & $\mathrm{Cl}$ \\
\hline Biochemical oxygen demand & BOD \\
\hline Chemical oxygen demand & COD \\
\hline Methylene blue active substances & MBAS \\
\hline \multicolumn{2}{|l|}{ Hardness } \\
\hline \multicolumn{2}{|l|}{ Phosphorous- as ortophosphate } \\
\hline Nitrogen- as amonium & N_AMON \\
\hline Nitrites & $\mathrm{NO}_{2}^{-}$ \\
\hline Nitrates & $\mathrm{NO}_{3}^{-}$ \\
\hline Organic nitrogen & N_ORG \\
\hline Total Kjeldahl nitrogen & NTK \\
\hline Disolved oxygen & DO \\
\hline \multicolumn{2}{|l|}{$\mathrm{pH}$} \\
\hline Total residues after evaporatión & TR \\
\hline \multicolumn{2}{|l|}{ Total disolved solids } \\
\hline \multicolumn{2}{|l|}{ Total suspended solids } \\
\hline Sedimentable solids at $10^{\prime}$ & $\mathrm{SS} 10 \mathrm{H}$ \\
\hline Sedimentable solids at $2 \mathrm{hs}$ & $\mathrm{SS} 2 \mathrm{H}$ \\
\hline \multicolumn{2}{|l|}{ Sulfate } \\
\hline Sulfide & S \\
\hline \multicolumn{2}{|l|}{ Phenols } \\
\hline \multicolumn{2}{|l|}{ Turbidity } \\
\hline Cadmium & $\mathrm{Cd}$ \\
\hline Zinc & $\mathrm{Zn}$ \\
\hline Copper & $\mathrm{Cu}$ \\
\hline Chromium & $\mathrm{Cr}$ \\
\hline Iron & $\mathrm{Fe}$ \\
\hline Manganese & $\mathrm{Mn}$ \\
\hline Nickel & $\mathrm{Ni}$ \\
\hline Lead & $\mathrm{Pb}$ \\
\hline
\end{tabular}

\section{Chemometric Methods of Analysis}

Multivariate techniques are methods of analysis generally recognized as very well known tools to study environmental problems $[9,10]$. From this kind of methods, Multivariate Curve Resolution (MCR) [11,12] has been selected as one of the most advantageous to have a close look of our system. To apply the MCR method, the minimax-scaled-matrix data base $\mathrm{M}_{270 \times 26}$ was reorganized by assembling every sampling campaign as a sub-matrix, which includes all its sampling sites as row vectors. These row vectors embrace the 26 physical-chemistry parameters measured. Not necessarily all these sub-matrixes have the same number of rows, but the same number of columns. Twenty one of these sub-matrixes were stacked to form the matrix $D_{270 \times 26}$, which contain the data spatially and temporally organized. Then, the matrix D allows MCR to analyze the data in space and time dimensions.

MCR is a bilinear based method of inverse calibration; it can be basically described as a matrix decomposition:

$$
\mathbf{D}=\mathbf{S L}^{\mathrm{T}}+\mathbf{E}
$$

where $\mathbf{D}$ is the data matrix, $\mathbf{S}$ is the scores matrix related with the objects and $\mathbf{L}$ is the loadings matrix related with variables. Every vector of $\mathbf{S}$ is associated with a vector of $\mathbf{L}$ through a product that represents a component. It is supposed that each component represents a kind of source (or combination of similar sources) which contributes to spoil the system. A sketch of the calculus is shown in Figure 5. The bilinear model in Equation (2) assumes that the major sources of the experimental data variance can be explained by a small number of components defining the two reduced-size factor matrices (scores and loadings). The model described by this equation assumes that the measured concentration of a contaminant (variable) in a particular sample is the sum of a reduced number of contributions of this contaminant coming from different sources. It is therefore a mixture analysis problem with unknown sources which have to be estimated from the analysis. Since the solution of Equation (2) is ambiguous, the matrix decomposition in this equation has to be performed under some constraints. The decomposition of Equation (2) is similar to Principal Components Analysis (PCA), but PCA decomposition is performed under orthogonal constraints, loadings normalization and maximum explained variance for the successive extracted components. Under these constraints, PCA provides unique solutions. However, these solutions are an abstract linear combination of the true experimental variance sources and, although they are very useful for data exploration and summary, in many cases they can be too complicated in terms of environmental interpretation. Although there are many good textbooks about PCA, we address to the interested reader to Jolliffe [13]. Unlike PCA, the matrix bilinear decomposition performed by MCR alternating-least-squares (ALS) uses softer natural constraints and as a result, the interpretation of loading and score profiles are more easy and reasonable from an environmental point of view $[9,14]$. Constraints used in this work during the MCRALS bilinear matrix decomposition were non-negativity and normalization of loadings to equal length as those used in previous works [14].

In this study another applied method was canonical correlation analysis (CCA). It is a way of measuring the linear relationship between two subsets of multidimensional variables. It begin when the original data set of $n$ variables and $p$ objects are grouped into two data sets, 
Madian; Box:25\%-75\%; Whisker:Non-Outlier Range

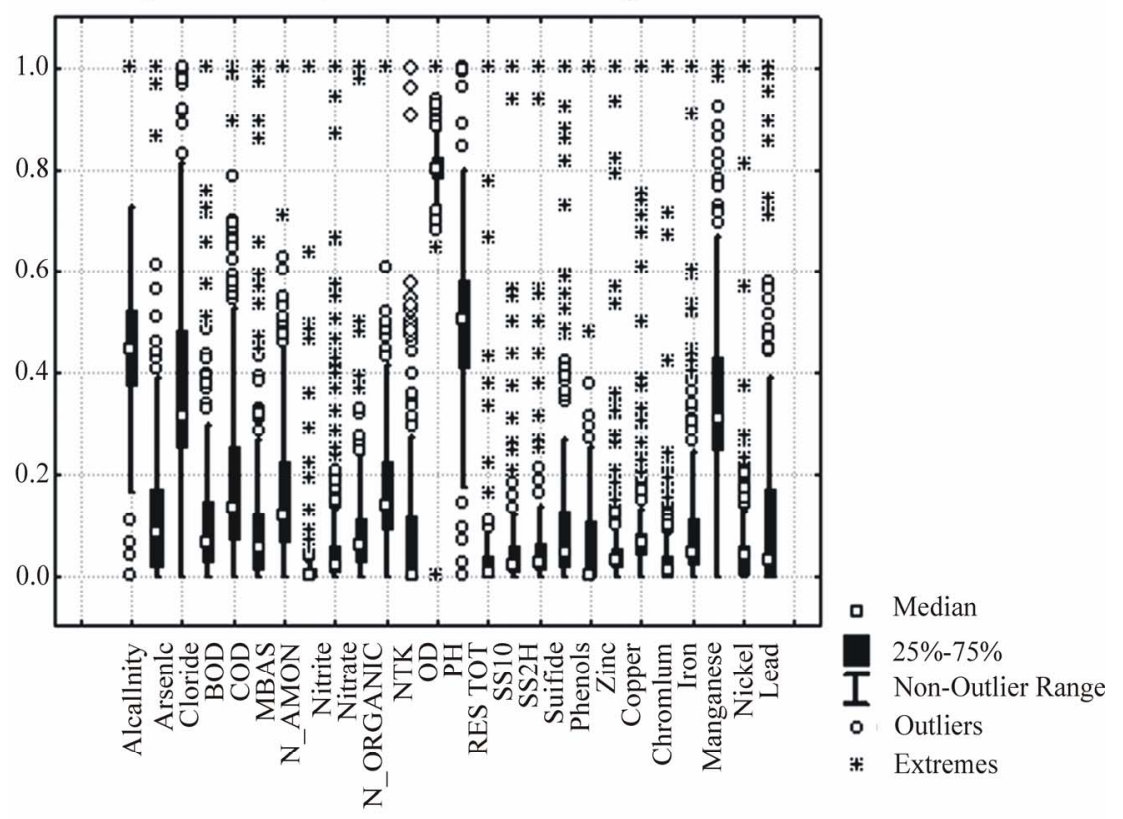

Figure 4. Spreads of all 26 variables scaled according to minimax algorithm. See equation 1 in the text.

\section{Bilinear Model $\quad \mathbf{D}=\mathbf{S} \mathbf{L}^{\mathbf{T}}+\mathbf{E}$}

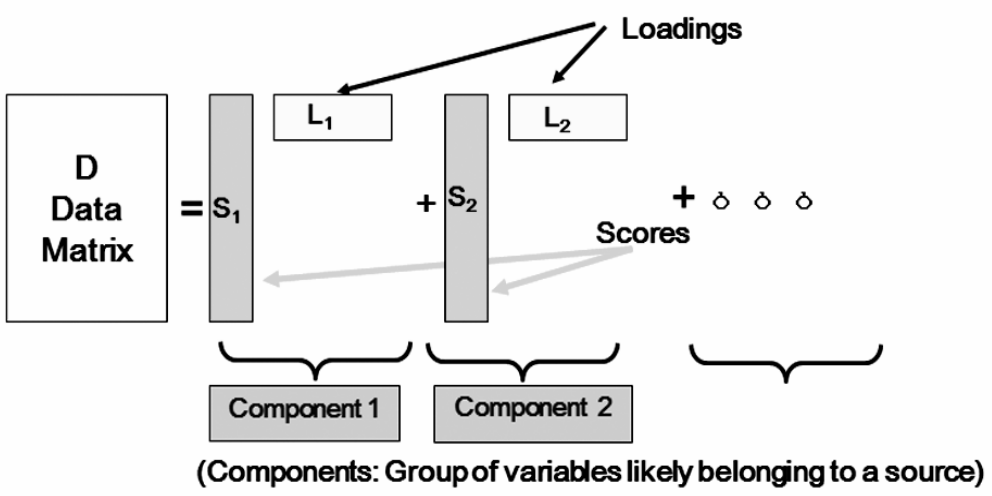

Figure 5. Sketch of the MCR calculus (see text).

$\mathbf{X}\left(p \times n_{\mathbf{X}}\right)$ and $\mathbf{Y}\left(p \times n_{\mathbf{Y}}\right)$, where $n=n_{\mathbf{X}}+n_{\mathbf{Y}}$, The method searches for a linear combination of the variables in $\mathbf{X}$ and another linear combination of the variables in $\mathbf{Y}$ to optimize the correlation between both sets. Then, the canonical correlations measure the strength of association between the two sets of variables. Hotelling developed CCA [10], becoming then a standard tool in statistical analysis, applied to economics, medical, and ecological studies $[15,16]$.

CCA proposes new variables $\mathbf{U}\left(p \times n_{\mathbf{X}}\right)$ and $\mathbf{V}\left(p \times n_{\mathbf{Y}}\right)$ presented in Equations (3) and (4).

$$
\begin{aligned}
\mathbf{U} & =\mathbf{X} \mathbf{A} \\
\mathbf{V} & =\mathbf{Y} \mathbf{B}
\end{aligned}
$$

The matrix $\mathbf{A}\left(n_{\mathbf{X}} \times n_{\mathbf{X}}\right)$ and $\mathbf{B}\left(n_{\mathbf{Y}} \times n_{\mathbf{Y}}\right)$, defining the transformation are chosen in orther that the correlation $\mathbf{C}$ $(\mathbf{U}, \mathbf{V})$ is maximum. Thus, it is possible to find new variables as combinations of the original ones, which reveal existing correlations between two different sets. Despite the fact that canonical variables are arbitrary, they can be then interpreted from the previous knowledge of the subject matter. Other methods, like principal component 
analysis (PCA) and univariate statistic, have been applied to check particular results.

\section{Results and Discussion}

Most of the chemical variables considered in this study overpass the concentration limits established as protection of aquatic life and consequently the water quality of the river is in general of poor quality due to pollutants coming from untreated domestic and industrial effluents poured directly on the river. The distribution of metalcations concentrations along the river is shown in Figures 6 and 7. Figure 6 cannot shows the extreme values (mg. $\mathrm{L}^{-1}$ ) of $\mathrm{Zn}$ (2.94), $\mathrm{Cr}$ (1.91), Ni (0.20) and $\mathrm{Pb}(0.11)$, but those of $\mathrm{Cd}$ and $\mathrm{Cu}\left(0.05\right.$ and $0.34 \mathrm{mg} \cdot \mathrm{L}^{-1}$ respectively). Fe and Mn have not been considered here because they have high concentrations due to their geological origin.

In these figures can be seen an increase of cation concentrations from RVI to RIII sampling points and then a progressive fall. The rational explanation for the increment of concentrations is the entrance of the Moron stream into the Reconquista River, with significant high values of dissolved salts. High levels of conductivity induce a compression of the double layer of water suspended particles,, thus decreasing the repulsion among them and consequentelyfavouring their coagulation and further precipitation in the main course [17] with the concomitant lowering of cation concentrations. The existence of a deposit of metals in the sediment between points RII and RI has been checked. This behaviour has been explained [18] through a water quality model that contemplates the adsorption of metals onto suspended particles and the precipitation into the sediments before reaching RI. Moreover, the average of sum of cations (without Fe and $\mathrm{Mn}$ ) for the sampling points RV (entrance point) and RI (exit point) have similar values without statistically significant differences $(0.535$ and 0.429 respectively); this means that the cations coming from channels do not produce a significant increment of metals content in the water quality of the river at RI.

Figure 7 shows the role of Fe and Mn. They are of geological origin and follow the same path than cations of different sources reinforcing the precipitation mechanism explained in the previous paragraph.

The interpretation of MCR's results is simplified if instead of analyzing the variables all together, they are separated in groups containing environmentally and chemically related variables. With this purpose we formed three groups of variables described in Table 2. Results for the first group are shown in Figure 8(a) (singular value decomposition (SVD) of the data matrix) and Figure 8(b) (level of significance for each variable according to their loading values). By selecting the first three factors of the SVD allow to reach $58.57 \%$ of the cumulative variance. The first row of Figure 8(b) shows a strong relationship among metals, $\mathrm{S}$ and $\mathrm{SS} 2 \mathrm{H}$, this is a usual expected result because metals that easily combine with sulphide form very insoluble compounds, ending up associated to solid suspended particles. Cappari [19] and Nader [18] have arrived to similar conclusions in the same site.

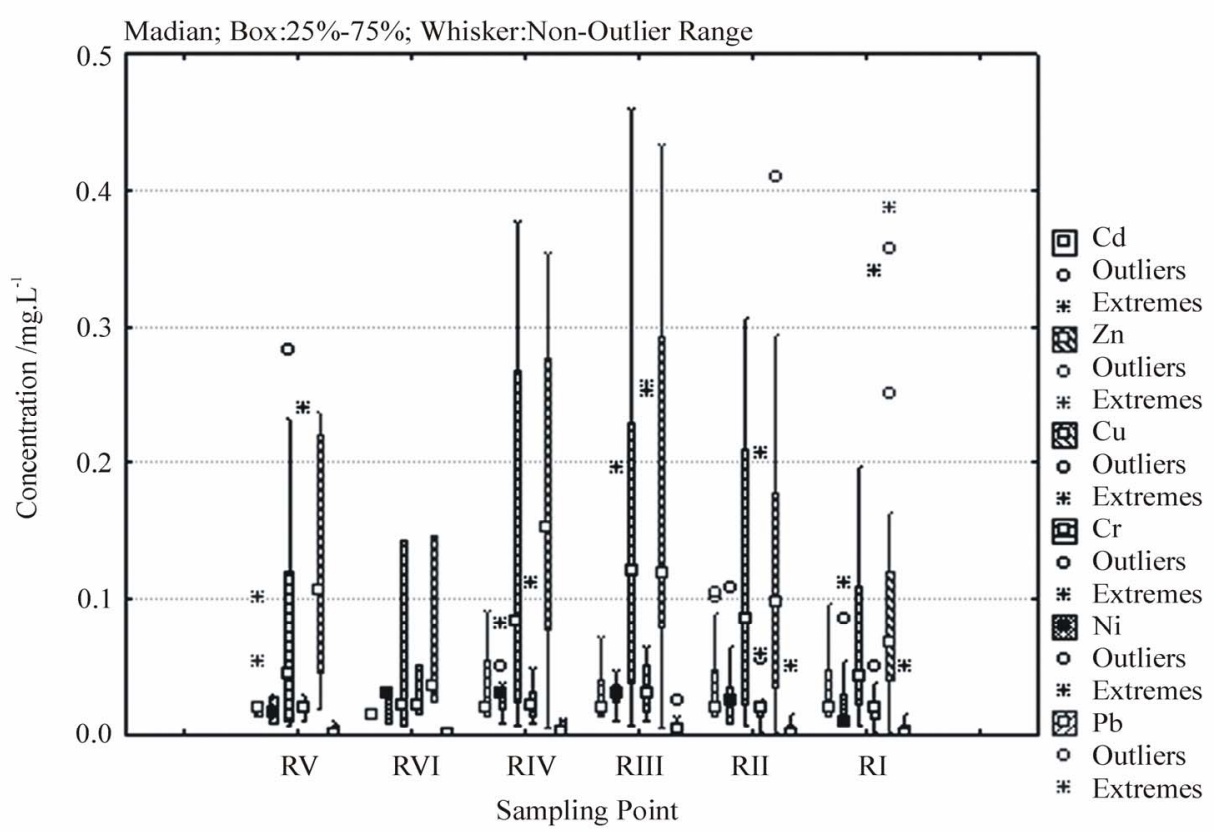

Figure 6. The distribution of metal-cation concentrations along the river in the sector under study. Fe and Mn are not shown. 


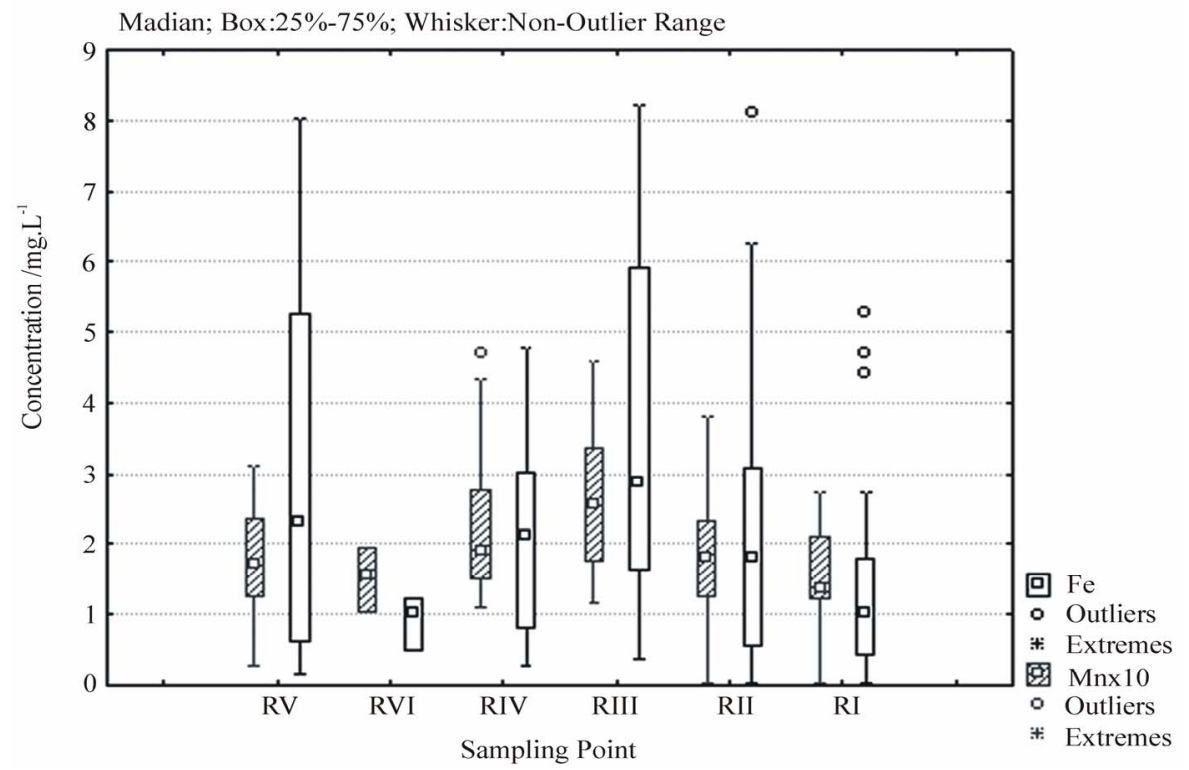

Figure 7. MCR result for metal-related variables.

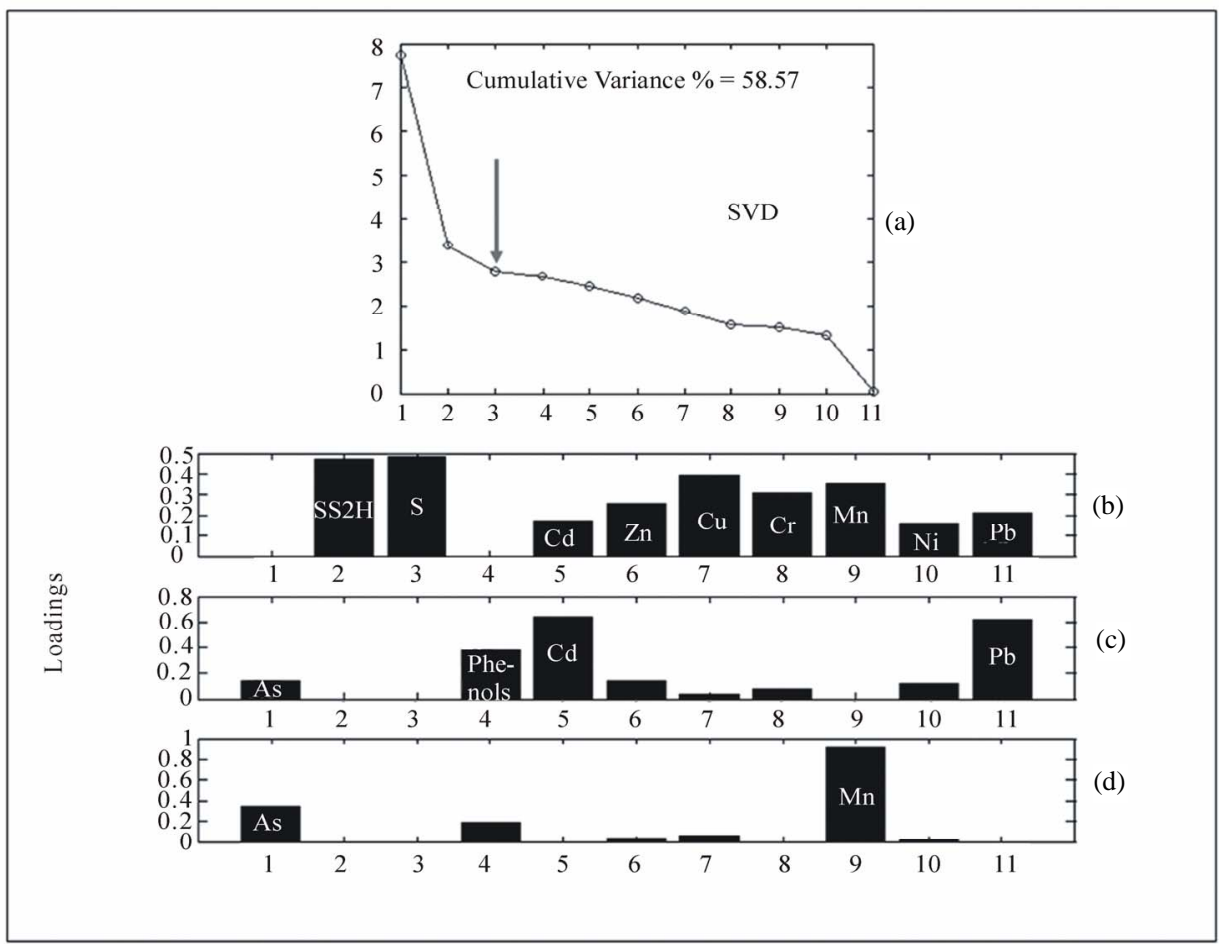

Figure 8. MCR result for nitrogen-related variables.

Table 2. Groups of variables for MCR analysis.

\begin{tabular}{|c|c|}
\hline Group & Variables \\
\hline $\begin{array}{c}\text { A } \\
\text { Metals related }\end{array}$ & SS2H, Phenols, S, Cd, Zn, Cu, Cr, Mn, Ni, Pb \\
\hline $\begin{array}{c}\text { B } \\
\text { Nitrogen related }\end{array}$ & MBAS, $\mathrm{NO}_{2}^{-}, \mathrm{NO}_{3}^{-}, \mathrm{N} \_\mathrm{ORG}, \mathrm{NTK}$, Phenols \\
\hline $\begin{array}{c}\mathrm{C} \\
\text { Oxigen related }\end{array}$ & Alkalinity, BOD, COD, DO, S, Phenols \\
\hline
\end{tabular}


The second row of Figure 8(b) shows that $\mathrm{Cd}$ and $\mathrm{Pb}$ are also associated, indicating a possible different source (or sources) for these contaminants, phenols are included in this group. The third row of Figure 8(b) shows the contribution of the sediment as a source of pollution. We did not consider Fe because it is of geogenic origin and its high concentrations are permanent around all the area. Its levels correlate with Mn concentrations, demonstrating that the latter one has the same origin, although with lower concentrations than Fe.

Figure 9 shows the MCR profiles of the nitrogen related variables: in this case three factors of the SVD represents $80.49 \%$ of accumulative variance. The significant contribution of MBAS, $\mathrm{NO}_{2}^{-}$, N_ORG, NTK and in low proportion phenols, are shown in the first row of Figure 9. These variables reveal the presence of reduced forms of nitrogen species as well as other species like phenols and surfactants. By relating the object scores with the sampling sites, it is possible to show that this component is mainly present in the lowest stream of the channels. The same procedure helped us to determine that the oxidized chemical species of nitrogen, $\mathrm{NO}_{3}^{-}$, appears in the upper stream of the channels. Moreover, the most reduced forms like $\mathrm{NH}_{3}$ and NTK are present in the river (see Figure 9).

The third group of variables, those related with oxygen, reinforces the previous result. It is shown in Figure $\mathbf{1 0}$ that dissolved oxygen is significantly present in the channels (upper stream) whereas a reductant media exist in the main river course, according to the weights of BOD, COD, S and phenols.

Canonical correlation has been used to explore other class of relationships, those that would be established between cations and variables related to organic material. Furthermore, we want to know if this possible relationship is the same at the river and at the channels. Within this frame, the $\mathrm{X}$ set includes variables of the $\mathrm{B}$ and $\mathrm{C}$ groups of Table 2 (DBO, DQO, MBAS, N_ORG and NTK); and the Y set includes metal concentrations (Cd, $\mathrm{Zn}, \mathrm{Cu}, \mathrm{Cr}, \mathrm{Mg}, \mathrm{Ni}$ and $\mathrm{Pb}$ ).

Figure 11(a) shows a high correlation between the $X$ and Y groups of variables with reference to the river, whereas for the channels, a low correlation is observed between the same groups of variables (Figure 11(b)).

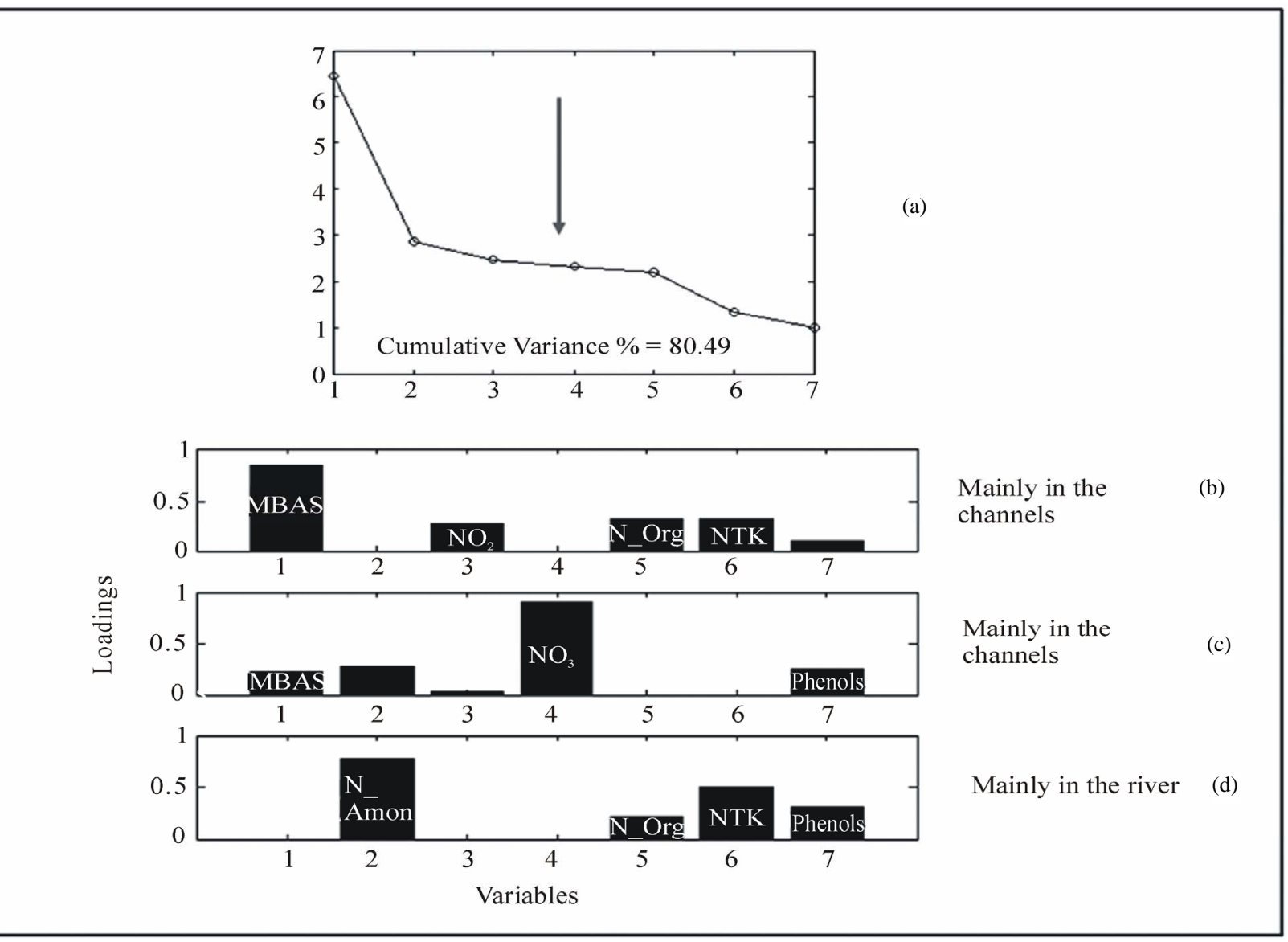

Figure 9. MCR result for oxygen-related variables. 


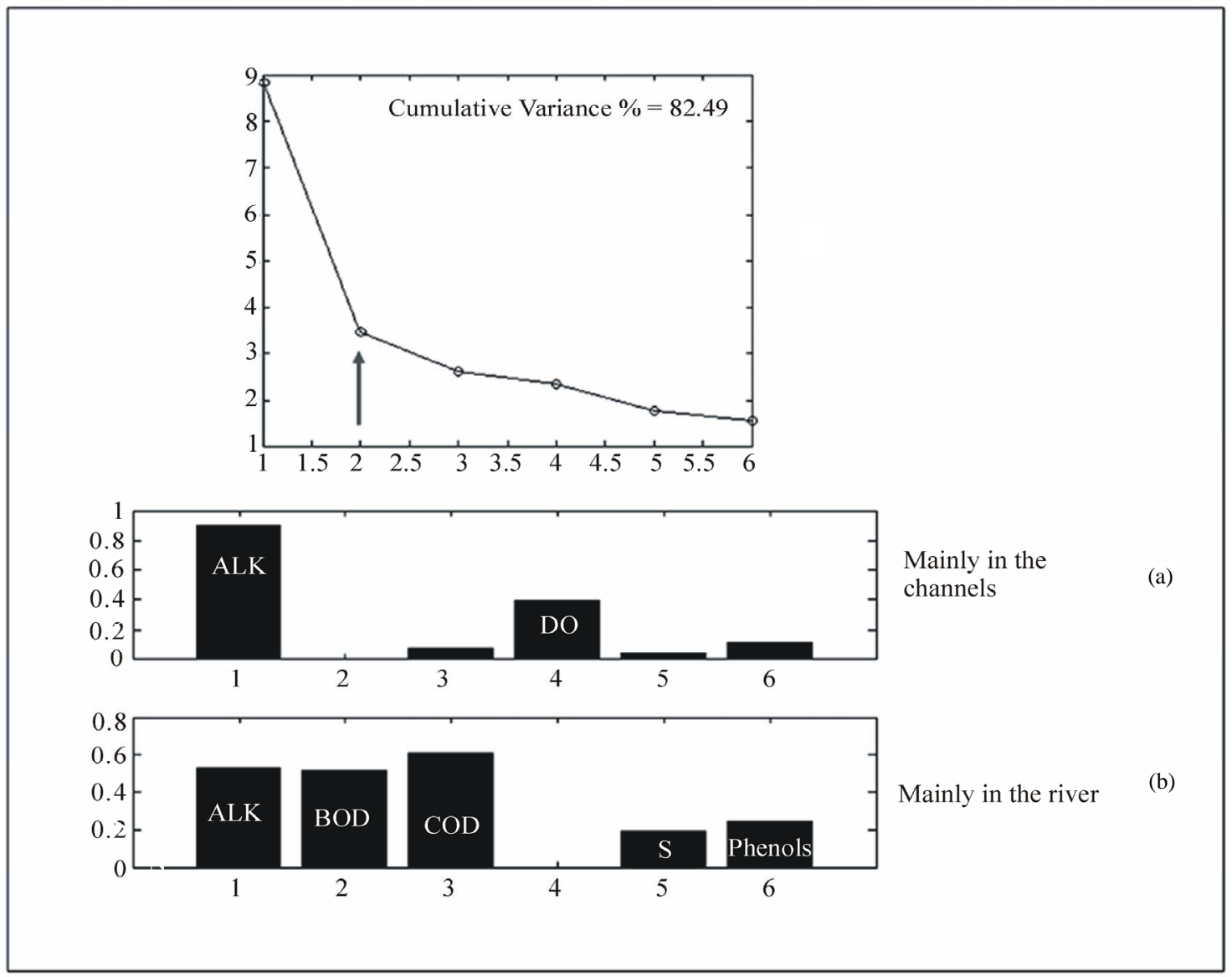

Figure 10. Correlation between groups of variables. Probably-complexating-agents and metallic (see text, Equations (5) and (6)). At the channels (a) and at the river (b).

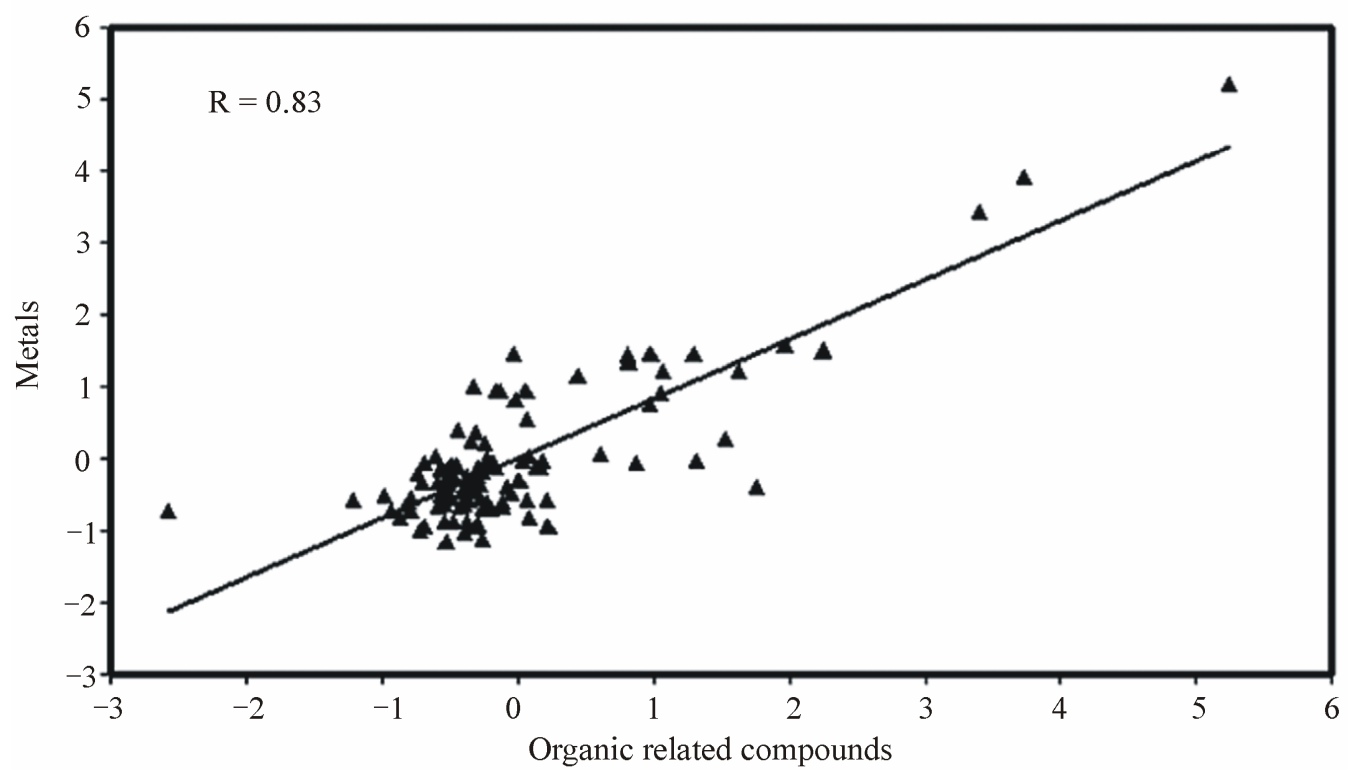

(a) 


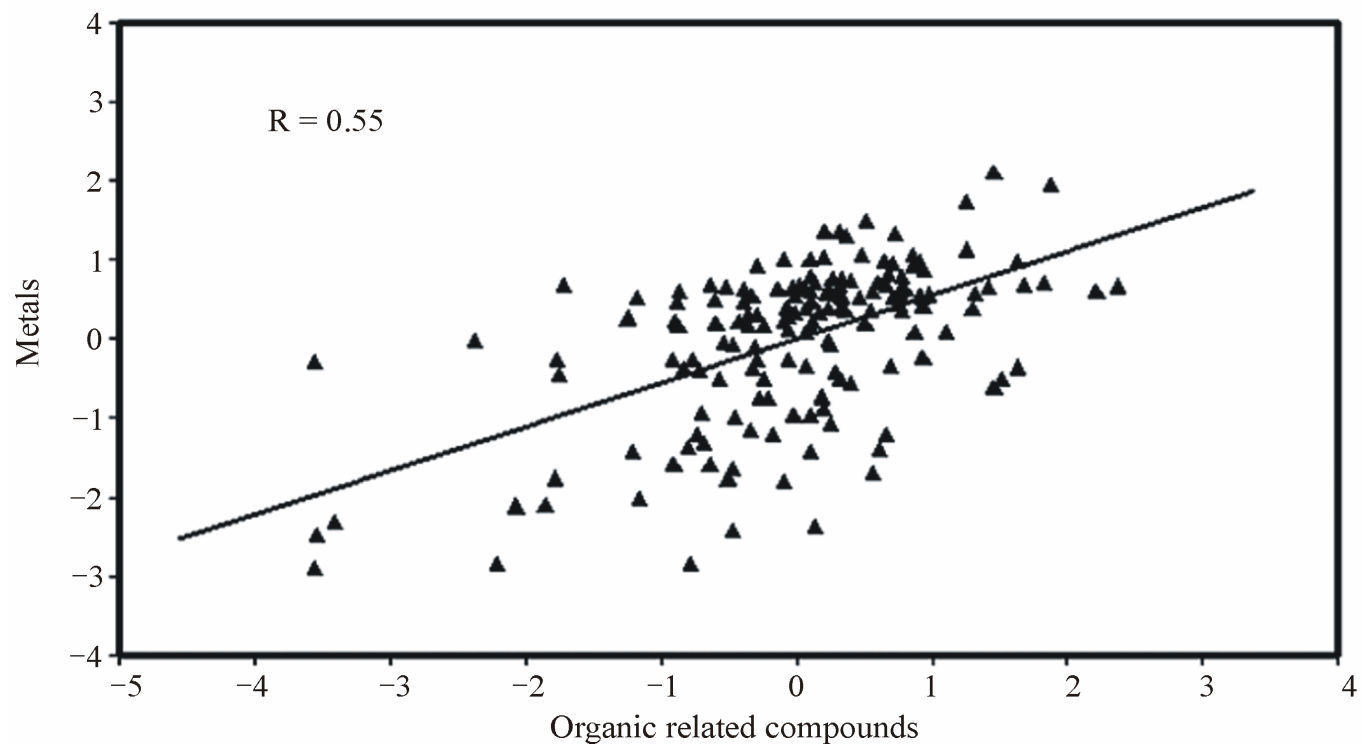

(b)

Figure 11. PCA loadings show correlations at the river (a) and at the channels (b).

The structures of the $\mathrm{U}$ and $\mathrm{V}$ values for the river (UR and VR) are :

$$
\begin{gathered}
\text { UR }=1.23 \% \text { DBO }+1.91 \% \text { DQO }+3.49 \% \text { MBAS } \\
+66.53 \% \text { N_ORG }+26.83 \% \mathrm{NTK} \\
\mathrm{VR}=3.54 \% \mathrm{Cd}+1.85 \% \mathrm{Zn}+1.30 \% \mathrm{Cu}+0.01 \% \mathrm{Cr}+ \\
0.07 \% \mathrm{Mg}+90.14 \% \mathrm{Ni}+3.07 \% \mathrm{~Pb}
\end{gathered}
$$

Since CAA also maximizes the correlation between each group of variables, it can also be highlighted that N_ORG and NTK are the most significant nitrogen related chemicals and, among metals, Ni contributes with the main part of the total variability.

A different behaviour is observed for the channels, showing a significant proportion of uncorrelated presence of chemicals associated with nitrogen and metals respectively. When the structure of the $\mathrm{U}$ and $\mathrm{V}$ variables for the channels (UC and VC) is analyzed for the first canonical components we obtain:

$$
\begin{aligned}
\mathrm{UC}= & 6.37 \% \text { DBO }+0.77 \% \text { DQO }+0.01 \% \text { MBAS + } \\
& 40.22 \% \text { N_ORG + 52.62\%NTK }
\end{aligned}
$$

$\mathrm{VC}=23.99 \% \mathrm{Cd}+6.32 \% \mathrm{Zn}+4.53 \% \mathrm{Cu}+20.04 \% \mathrm{Cr}+$

$$
\text { 8.16\% Mg }+8.31 \% \mathrm{Ni}+28.72 \% \mathrm{~Pb}
$$

The structure of the nitrogen related variables is very similar for either channels or river sites but, the composition of the metal variables is completely different. Thus, a mixture of metals, lightly correlated with nitrogen variables is found in channels monitored sites while these nitrogen variables show a strong correlation with $\mathrm{Ni}$ concentrations for the river waters.

We looked for more evidence supporting these results through principal components analysis (PCA). By de- veloping two PCA with the same variables used for CCA, one for the river and the other one for channels, the obtained results show agreements with those of CCA (see Figures 12(a) and (b)). The PCA loadings at the river (Figure 12(a)) show a good correlation among these variables with exception of NTK, MBAS and Cadmium. It is remarkable the correlation of all metal cations with other variables related to organic materials and organic nitrogen, possibly suggesting the complexation of cations with organic matter. This is consistent with previous results that found high levels of dissolved metals in the main course of the river [14]. The channels (Figure 12(b)) do not show the same correlation with organic nitrogen, reinforcing the results found with CCA. The difference between channels and river could be explained because organic nitrogen have much higher median in the river $\left(11.80 \mu \mathrm{g} \cdot \mathrm{L}^{-1}\right)$ than in the channels $\left(6.85 \mu \mathrm{g} \cdot \mathrm{L}^{-1}\right)$ while the median of the sum of cations (without considering iron and manganese) keep almost the same: 0.10 $\mu \mathrm{g} \cdot \mathrm{L}^{-1}$ for channels and $0.15 \mu \mathrm{g} \cdot \mathrm{L}^{-1}$ for the river.

\section{Conclusions}

Univariate and multivariate statistical techniques are both of importance to analyze a multivariate problem. Complex multivariate systems like environmental ones require a sequential application of both methods. It is preferable to start with multivariate methods to arrive at general and clear conclusions, and then, to check those possible doubtful points or conclusions with univariate tools.

Because environmental systems involve many variables of different origins, like chemical, physical, meteorological, geological, etc., it is difficult to tray to relate 


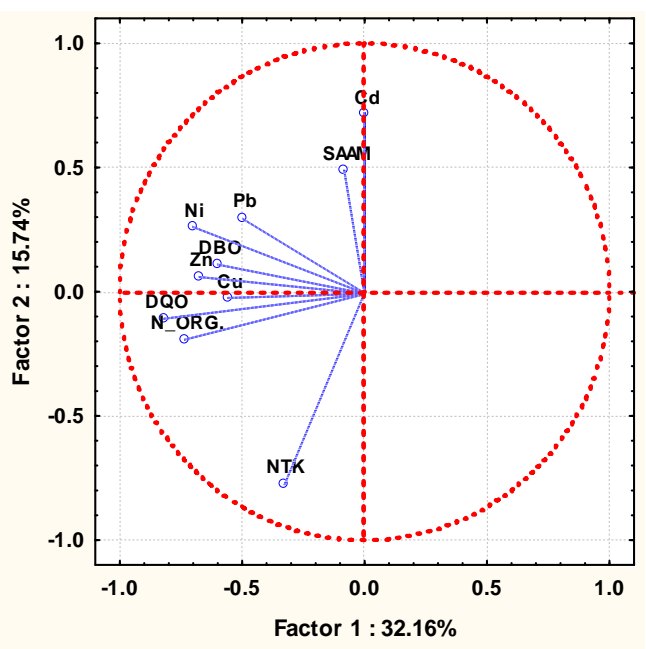

(a)

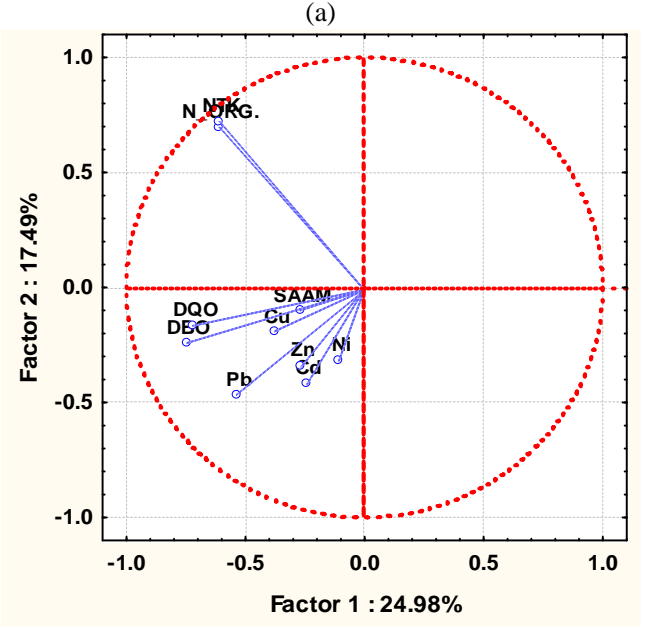

(b)

Figure 12. Distribution of Fe and $\mathrm{Mn}$ along the river.

all variables at the same time. To facilitate the analysis, the variables should be divided into groups according to their environmental compatibility, as we explained in the results section.

The river is already highly polluted at the point in which it reaches the studied sector. Its contamination by most of the measured pollutants overpasses the limits of protection of aquatic life. Along the studied sector, the presence of metals seems to come from at least three different kinds of sources as the MCR result shows.

Regarding metal-cation concentrations, there are no significant differences between the ones measured at the entrance from those determined at the exit of the studied sector. Even though the Arroyo Morón, one of the considered streams, significantly increases the concentration of dissolved salts (and in this way the cation contents) in the main river course from RVI to RII; a deposit of metals has been identified between RII and RI, probably due to precipitation with sulphides and adsorption to sus- pended particulate material, all of them falling to the sediments. This situation requires the management of the sediments in this area as hazardous waste.

Finally, at their sources, the channels show compatible levels of DO, BOD and COD and oxidized species of nitrogen for aquatic life protection. The contamination of channels increases along their courses, the content of dissolved oxygen diminishes toward the river because the presence of shanty towns in the area without sewer services and the direct input of untreated industrial effluents. When channels arrive to the main stream, they end up polluting the river with organic matter coming from waste, sewage, etc., although the river is in worse condition than channels. These channels contribute to increase the pollution of the river, either of its water or its sediment. The lack of sewers is one of the main causes of this type of pollution.

\section{Acknowledgments}

This study is part of an International Atomic Energy Commission (IAEA) project (RLA /1/010) 'Improvement of the management of contamination of surface water bodies contaminated with heavy metals'. As a complementary project, a bilateral Argentine-Slovenian agreement (SLO/08/12) was established in order to analyze the data provided by the water quality sampling plan. Support has also been received from ANPCyT project PIC07 01216 "Movilización de Contaminantes en Sistemas Naturales”.

\section{REFERENCES}

[1] World Bank, "Environment Matters,” Annual Review 2003, Water Supply and Sanitation, p. 23.

[2] Aguas Argentinas, Obras Sanitarias de Buenos Aires, Instituto Ringuelet y Servicio de Hidrografía Naval, "Calidad de las Aguas de la Franja Costera Sur del Río de la Plata, (San Fernado-Magdalena),” Consejo Permanente para el monitoreo de la Calidad de Aguas de la franja Costera Sur del Río de la Plata (ed.), Secretaría de Obras Públicas, Dirección Nacional de Gestión de los Recursos Hídricos, anexos I y II, Buenos Aires, 1997.

[3] G. Kiely, "Ingeniería Ambiental,” McGraw Hill, Boston, 1998.

[4] D. L. Massart, B. G. M. Vandeginste, S. N. Deming, Y. Michotte and L. Kaufman, "Chemometrics: A Textbook," Elsevier, Amsterdam, 1988.

[5] D. L. Massart, B. G. M. Vandeginst, L. M. C. Buydens, S. De Jong, P. J. Lewi and J. Smeyers-Verbeke, "Hanbook of Chemometrics and Qualimetrics,” Elsevier, Amsterdam, 1997.

[6] J. W. Einax, "Chemometrics in Environmental Chemistry-Applications,” Springer-Verlag, Berlin, 1995.

[7] J. W. Einax, H. W. Zwanziger and S. Geiss, "Chemometrics in Environmental Analysis," VCH-Weinheim, 
Germany, 1997.

[8] S. Verboven and M. Hubert, "Libra: A Matlab Library for Robust Analysis," Chemometrics and Intelligent Laboratory Systems, Vol. 75, No. 2, 2005, pp. 127-136. doi:10.1016/j.chemolab.2004.06.003

[9] M. Felipe-Sotelo, L. Gustems, I. Hernández, M. Terrado and R. Tauler, "Investigation of Geographical and Temporal Distribution of Tropospheric Ozone in Catalonia (North-East Spain) during the period 2000-2004 Using Multivariate Data Analysis Methods," Atmospheric Environment, Vol. 40, No. 38, 2006, pp. 7421-7436. doi:10.1016/j.atmosenv.2006.07.013

[10] H. Hotelling, "Relations between Two Sets of Variates," Biometrika, Vol. 28, No. 3-4, 1936, pp. 321-377.

[11] R. Tauler, "Multivariate Curve Resolution Applied to Second Order Data," Chemometrics and Intelligent Laboratory Systems, Vol. 30, No. 1, 1995, pp.133-146. doi:10.1016/0169-7439(95)00047-X

[12] R. Tauler, A. Smilde and B. Kowalski, "Selectivity, Local Rank, 3-Way Data Analysis and Ambiguity in Multivariate Curve Resolution,” Journal of Chemometrics, Vol. 9, No. 1, 1995, pp. 31-58. doi:10.1002/cem.1180090105

[13] T. Jolliffe, "Principal Component Analysis," SpringerVerlag, New York, 2002, p. 26.

[14] M. Terrado, D. Barceló and R. Tauler, "Quality Assessment of the Multivariate Curve Resolution Alternating
Least Squares (MCR-ALS) Method for the Investigation of Environmental Pollution Patterns," Environmental Science \& Technology, Vol. 43, No. 14, 2009, pp. 5321-5326. doi:10.1021/es803333s

[15] C. J. F. Ter Braak, "Canonical Correspondence Analysis: A New Eigenvector Technique for Multivariate Direct Gradient Analysis,” Ecology, Vol. 67, No. 5, 1986, pp. 1167-1170.

[16] S. Becker, "Mutual Information Maximization: Models of Cortical Self-Organization Network," Computation in Neural Systems, Vol. 7, No. 1, 1996, pp. 7-31.

[17] W. Stum and J. Morgan, "Aquatic Chemistry. Chemical Equilibria and Rates in Natural Waters," 3rd Edition, John Wiley \& Sons, Inc., New York, 1995.

[18] G. Nader, "Modelización del Transporte de Metales en el río Reconquista (entre ex ruta 8 y Panamericana): Etapas de Conceptualización, Formulación y Calibración,” Ph.D. Dissertation, Universidad Nacional De San Martín, San Martín, 2009.

[19] G. Cappari, "Evaluación de la Calidad de Agua Superficial del Río Reconquista a la Altura del Partido de San Martín Mediante Estudios Ecotoxicológicos en dos Oportunidades de Muestreo (2007-2008) y Caracterización de los Sedimentos Obtenidos en el Mismo Tramo de la Cuenca,” Ph.D. Dissertation, Universidad Nacional De San Martín, San Martín, 2008. 